\title{
Paralelos a los sillares grabados de Rasines, Cantabria
}

\author{
Maria Paz Garcia-Gelabert Pérez
}

INTRODUCCIÓN*

El objetivo de este trabajo se concreta en un sólo punto: dar a conocer paralelos a los sillares grabados, pertenecientes a los muros de la iglesia de San Andrés de Rasines '. Mas antes permitaseme bosquejar unas notas acerca de estos sillares y del entorno en que se hallaron.

Cantabria fue la cuna de numerosos maestros canteros que trabajaron en el Renacimiento y durante épocas anteriores, en el Románico y en el Gótico. Y un número importante de estos maestros tuvieron su acogida en la llamada Junta de Trasmiera ${ }^{2}$, ya que buena parte de las familias de Trasmiera se dedicaron a este oficio de generación en generación, en los siglos $X V$ y $X V I$ y probablemente con anterioridad a ellos. A todos se les denomina maestros canteros de Trasmiera, son: los Gil de Hontañón (en algunos documentos son nombrados como de Trasmiera,

* Agradezco a Dñ. María Ealo de Sa la posibilidad de acceder al conocimiento de las piedras grabadas, a D. José Gabriel Viar, alcalde de Rasines el apoyo recibido para realizar el trabajo, y a D. Esteban Moreno y D. Pedro García su colaboración en la recogida de datos durante la prospección y la excavación arqueológica.

1 Ealo de SA, M., Catálogo de los petroglifos de Rasines (Cantabria). Santander 1990.

2 Sobre los maestros, cfr., SOJA Y LOMBA, Los maestros canteros de Trasmiera. Madrid 1935. Martinez y SAnz, Manuel, Historia del templo de la catedral de Burgos. Burgos 1866. Boletin de la Biblioteca Menéndez y Pelayo, año V. 1923. Pereda de La Reguera, Manuel, Rodrigo Gil de Hontañón. Selección y estudios. Santander 1951. Arquitectos importantes trasmeranos son Juan de la Sierra Becerraiz, vecino de Secadura; Bernabé de Hazas; Francisco del Pontón, vecino de Galizano; Andrés de la Sierra, también de Secadura; Agustín Corlado y García de Ribas, los dos vecinos de San Pantaleón de Aras; Francisco del Rio, cura de Secadura. 
en otros no), los Solorzanos, los Herreras, los Arces, los Cagigas, los Castillos, los Riaños, los Rivas y los Vegas, entre otros.

De la dinastía de los Gil de Hontañón se conoce a Juan Gil, apellidado el Viejo, que nació entre 1460 y 1465, y murió quizás sobre el 1522. Fue vecino de Rasines. Es el padre de Rodrigo Gil de Hontañón, Juan Gil el Mozo y Maria Gil. De los tres sólo es hija legítima María. Acerca de Rodrigo se ha de indicar que pudo nacer en Hontañón, barrio del pueblo de Carasa, cercano a Rasines (no existe pueblo en la actualidad que se denomine Hontañón), en los primeros años del siglo XVI. Él se dice en los documentos vecino de Hontañón. Fue educado por su padre; y con él y con su hermana María, residió en Rasines, al menos en sus años jóvenes. A su muerte fundó una capilla en esta localidad. En su testamento se trata de la fundación de la capilla de San Andrés y se cita a Diego Gil de Gibaja Hontañón, desposado con María de Rivera, sobrina de Rodrígo. Gil de Gibaja se compromete a hacer la capilla ${ }^{3}$. Ahí está pues, una construcción religiosa, tal vez ligada a la iglesia de San Andrés aunque nada se puede asegurar.

De principios del siglo XVII hay documentos que atestiguan que la iglesia de San Andrés fue trazada por Rodrigo Biyar de Rasines y Pedro de la Torre Bueras ${ }^{4}$. En el transcurso de la construcción se sucedieron los maestros y las modificaciones al proyecto inicial. Maestro de cantería de San Andrés es Juan de Monasterio. El pórtico es de Andrés de Bolde y el retablo de Jerónimo de Angulo y Domingo del Rivero.

Hasta aquí unas breves noticias sobre la iglesia de la que formaron parte los sillares grabados, colocados por los maestros canteros en el basamento de la torre y tal vez algunos en el arco de la puerta.

\section{LOS SILLARES GRABADOS DE RASINES}

La torre de la iglesia se derrumbó hace algunos años y el material de derrumbe fue colocado en un gran montón en una explanada contigua a la iglesia. Alli fueron descubiertos los sillares grabados, que pronto llamaron la atención de los curiosos. Los sillares grabados son minoría con respecto a los lisos; son algo más de una treintena. Como el resto

\footnotetext{
3 Pereda de la Reguera, Manuel, Rodrigo Gil de Hontañón. Selección y estudios.

${ }^{4}$ Archivo Histórico Provincial, prot. leg. 3.434 , fols. $87-89$.
} 
de la iglesia se halla en pie no se puede conocer si hay más de aquellas características formando parte de las paredes.

Los sillares están grabados en las caras no vistas, por lo que en la superficie de los muros nunca podrian verse los grafismos. El hecho de haber permanecido ocultos, sin contaminación alguna, hace que aparezca la talla fresca, apreciándose claramente las marcas del puntero. No tienen, pues, huella de desgaste. Entre los grabados hay restos de la argamasa empleada para unir la sillería.

Los grafismos, que presentan en sus dos caras ocultas, son esquemáticos, ornamentación ramiforme, triángulos, espigas, líneas curvilíneas paralelas verticales, unidas por otra horizontal (Figs. 1-2).

En la primera toma de contacto con los sillares, la doctora López Monteagudo y quien suscribe, apuntamos como hipótesis de trabajo que las piedras podrian ser de épocas antiguas y haber sido reutilizadas en la construcción de la iglesia. Para esta afirmación nos basamos en los paralelos existentes para las piedras talladas con incisión en otros lugares, pertenecientes a las edades del bronce y hierro europeos. Este hecho produjo desde el primer momento unas perspectivas de gran interés arqueológico.

Signos similares en forma de cruces se documentan, entre otros rasgos, en menhires franceses, ligados al arte de los megalitos, a 2.3001.800 a. C. ${ }^{5}$. Concretamente los menhires de Couches (Epoigny), estudiados por Louis Lagrost, constituyen un paralelo muy próximo a la simbologia de Rasines ${ }^{6}$.

Piedras muy semejantes a las de la iglesia de San Andrés de Rasines, formaban parte del paramento circular de tres túmulos de Gosberg (Baviera), pertenecientes a mediados de la Cultura de los Campos de Urnas en Centroeuropa ${ }^{7}$. Se trata de un espacio de $100 \mathrm{~m}^{2}$ en el que se distribuyen 11 túmulos, de los que ocho conservan su círculo de piedras.

${ }^{5}$ DeChelette, J., Manuel d'Archéologie préhistorique et celtique, I. Paris 1928/1987. Giot, P. R., Helgouach, J. L., Monnier, J. L., Préhistoire de la Bretagne, Ouest France Université, 1979. Renfrew, C., Les origines de l'Europe. Paris 1983. Abelanet, J., Signes sans paroles. París 1986. BriARD, J., Mythes et symboles de l'Europe préceltique. París 1987. 59 .

'Dolmens et menhirs de Bourgogne, Revue Archeologia, núm. 238, 1988, págs. 52-

T Mulier-Karpe, H., Handbuch der Vorgeschichte, Band IV/1 Bronzezeit. München 1980 , págs. $261-264$ y 841 , taf. $427 \mathrm{E}$. 


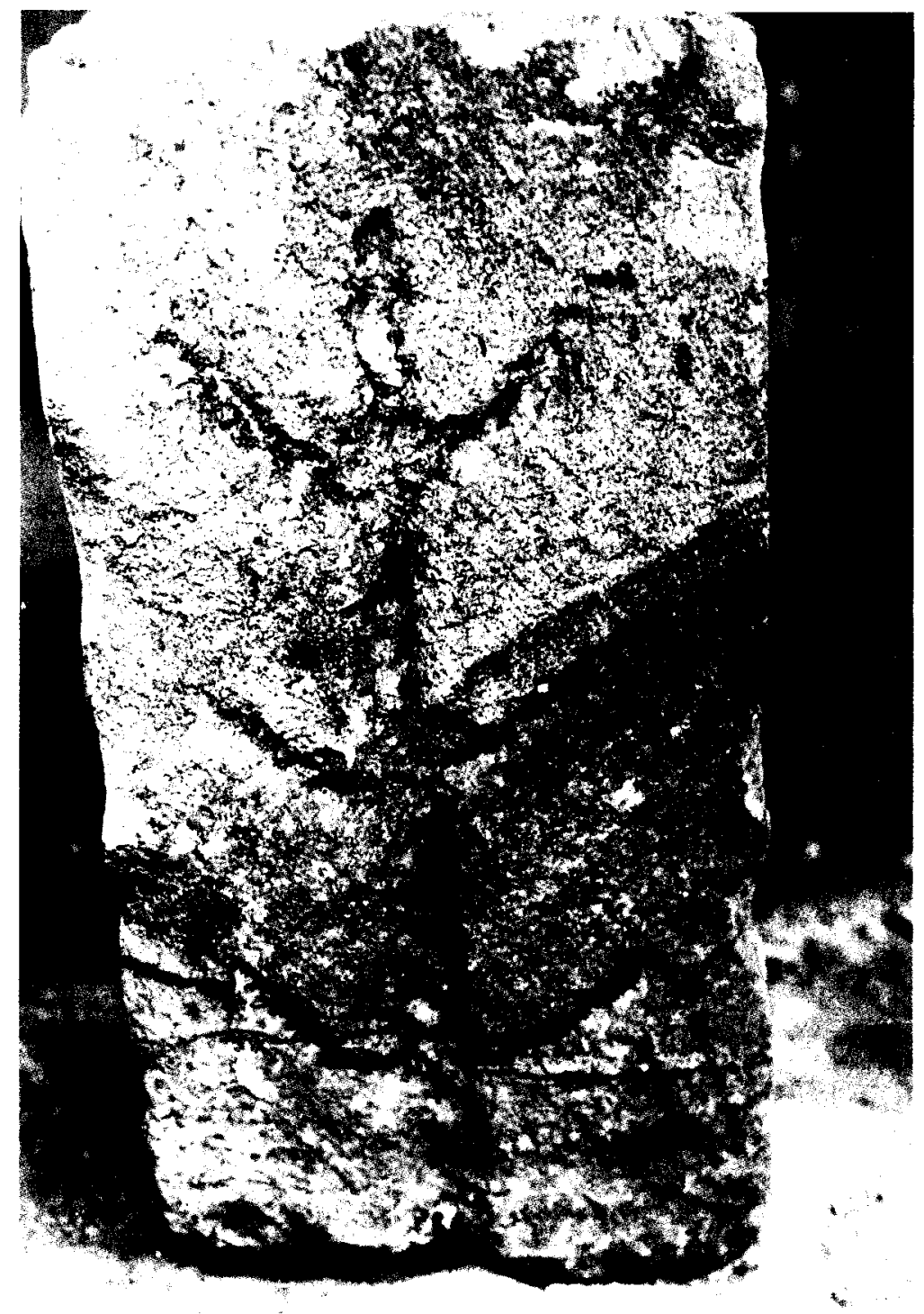

Fig. 1. Sillar grabado de la iglesia de San Andrés de Rasines, Cantabria. 


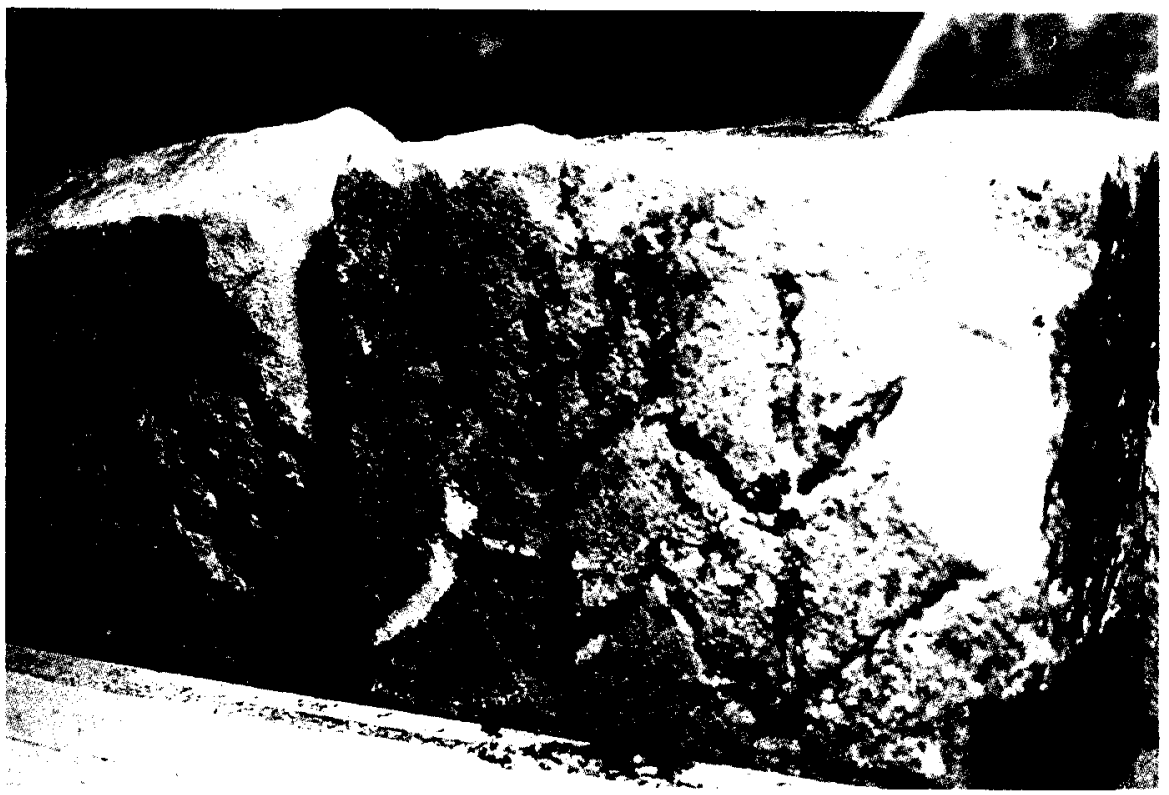

Fig. 2. Sillar grabado de la iglesia de San Andrés de Rasines, Cantabria.

En algunas de las sepulturas se han encontrado restos de cerámica y bronce $^{8}$.

Una piedra de granito de $40 \mathrm{~cm}$ de altura, $30 \mathrm{~cm}$ de ancho y $10 \mathrm{~cm}$ de grosor, con ornamentación ramiforme, prácticamente idéntica a algunas de Rasines y de similar tamaño, fue hallada en las excavaciones llevadas a cabo por Mario Cardozo en 1950 en el castro de Briteiros (Minho, Portugal), perteneciente a la Edad del Hierro ${ }^{9}$.

Acerca de la procedencia definitiva de los sillares grabados, en el caso de que fueran reutilizados, barajamos numerosas hipótesis. Una de ellas dirigía su origen a un monumento que estuviera localizado en el solar o inmediaciones de la iglesia. Ello podría tener base, pues el interés

${ }^{8}$ Henning, H., Die Grab und Hortfunde der Urnenfelderkultur aus Ober und Mittelfranken, 1970, págs. 70 ss. A. JOCKENNHOVEL, PBF VIII/1, 1971, pág 102.

9 Cardozo, M., Excavãçoes na Citânia de Briteiros, Revista de Guimâraes, 1950 , págs. 518-526, fig. 4.1. Idem, Citânia de Briteiros e Castro de Sabroso, Guimâraes, 1971, pág. 34, est. XXI. 2. Idem. Catalogo do Museu de Martins Sarmento, Guimâraes, 1972, págs. $176-177$. 
histórico y arqueológico del emplazamiento de la iglesia de San Andrés de Rasines y de los parajes circundantes, vienen avalados por su situación privilegiada en una zona de paso entre el mar y el interior, desde los antiguos tiempos prehistóricos, por la existencia de minas de hierro y galena y por el poblamiento continuado desde época prehistórica.

En la Prehistoria la zona estuvo habitada, de ello son testimonio las cuevas, entre las que destacan las del Valle y la de San Roque. Ambas son ricas en restos arqueológicos desde el Paleolítico hasta, al menos, la Edad del Bronce. Asimismo en el área hay un grandioso campo tumular, situado en la cañada que asciende al alto de Lodos. Está compuesto de túmulos de medianas dimensiones, aunque hay varios de proporciones importantes. Están construidos con lajas de piedra, que abunda en la zona, y probablemente en su época recubiertos de tierra. En los que han destruido los saqueadores suele aparecer una gran cista central de piedra. Es bien sabido el profundo interés de Roma por aquellas tierras conquistadas en las que había minerales. Pues bien, en el municipio de Rasines hay abundantes vetas de mineral de hierro y galena, con huella de haber sido explotadas intensamente. Asimismo hay numerosos puntos de fundición, que están indicando una actividad continuada desde épocas antiguas. Además, la presencia romana se ha revelado por varias inscripciones y restos arquitectónicos.

\section{EXCAVACIÓN EN EL ENTORNO DE LA IGLESIA DE SAN ANDRÉS}

Los sillares pudieron haber sido reutilizados o bien tallados y grabados durante la construcción de la fábrica, dos hipótesis a barajar. Una teoria que también hemos valorado acerca de los grafismos es su origen funcional. Es decir, los dibujos incisos tendrian como misión facilitar la mejor unión entre sillares y la adherencia de la masa. Aún en función de la primera hipótesis, solicitamos permiso de excavación a la Consejería de Cultura de la Diputación Regional de Cantabria, con el fin de tratar de localizar el posible lugar de origen de los sillares grabados. Dicho organismo determinó "autorizar la realización de excavaciones arqueológicas de urgencia en el exterior de la iglesia de San Andrés de Rasines, bajo la dirección de las arqueólogas Guadalupe López Monteagudo y $\mathrm{M}^{\mathrm{a}} \mathrm{Paz}$ Garcia-Gelabert Pérez".

Durante la investigación arqueológica se encontró un asentamiento romano en el solar situado al norte de la iglesia. Dicho asentamiento está señalado por cerámica sigillata hispánica tardía (datación siglo IV) y por 
una serie de muros de cimentación, compuestos de piedra irregular aristada y cantos de río de tamaño mediano. Es posible que en un momento dado la explotación de las minas haya estado en manos de elementos itálicos, y los restos cerámicos y de muros, detectados en la iglesia de Rasines, estén asociados a ellos. Residuos más antiguos, de cualquier época, no han aparecido en toda la extensión excavada, con lo que queda descartada absolutamente, en las inmediaciones de la iglesia, la existencia de un asentamiento afín con la iconografía de los sillares, conforme a los paralelos expuestos. En cambio, durante la investigación, hubo varios hallazgos datables en tiempo moderno, sobre todo los recuperados en la nave, que por el derrumbe, quedó al descubierto. La mayoría se recogió en el interior y fuera de un depósito, construido con argamasa y piedra menuda, rematado en un brocal redondeado irregular. Éste sobresalía del nivel de la nave, hallándose, según comunicación oral de unos vecinos, muy cerca de la pila bautismal. Pudo ser un lugar donde se recogian los objetos de culto, inutilizados por rotura o sustituidos por otros más ricos, mas consagrados por el uso. Contenía cerámica vidriada: cuencos y platos, una concha de bautismo de porcelana blanca, una jarrita de las utilizadas para contener el vino y el agua de la consagración y diferentes objetos metálicos.

El subsuelo del recinto de la nave, como fue usual, estaba destinado a necrópolis. Excavamos y aislamos numerosos esqueletos. Los huesos estaban muy revueltos, gracias a la labor de los violadores-buscadores de objetos de valor, tal vez contemporáneos o poco más de los cadáveres. Solamente hallamos sobre un esqueleto, que conservaba la mayoría de sus huesos, un maravedi de la época de Felipe III (fecha: 1598-1602, ceca: Burgos, metal: vellón, tipo: blanca) (según estudio del prof. Manuel Abad).

En resumen, la excavación realizada en el exterior y nave de la iglesia de San Andrés no ha aportado ningún dato esclarecedor acerca de los sillares grabados. Esto no constituye, en definitiva, una respuesta concluyente a nuestras dudas, dada la reducción presupuestaria y espacial de la autorización concedida, en relación con el proyecto original presentado, en el que se proponía la excavación de sondeo del exterior de la iglesia y la prospección sistemática en los parajes circundantes.

Al finalizar la campaña de excavación, el equipo investigador tuvo conocimiento de la existencia de otros sillares grabados, al parecer de similares caracteristicas a los de Rasines, situados en el convento franciscano de Frias (Burgos) ${ }^{10}$. También supimos de otros en las iglesias

${ }^{10}$ D. José Angel Rodriguez Fernández y Dña. Elena Helguera Hierro, nos facilitaron 
cántabras de Cereceda y Udalla. De ellos tratamos a continuación, como paralelos más inmediatos a los de la iglesia de San Andrés. A pesar de haber hallado unos paralelos tan similares no se da la investigación por concluida hasta no haber hecho los cálculos precisos en cuanto a la ubicación de los sillares de Rasines, ya que es posible que uno de ellos fuera la clave del arco de una puerta, en cuyo caso no habría reutilización posible, sino que el grafismo estaría adecuado a su marco.

\section{PARALELOS A LOS SILLARES GRABADOS DE RASINES}

En lo que fue convento de la Orden de San Francisco, en Frías (Burgos), se halló un paralelo exacto a los sillares grabados de Rasines (Figs. 3 a 6).

El convento fue sometido a penosos avatares desde su fundación y, sobre todo, en época moderna ${ }^{11}$. Consta que durante la revolución francesa los monjes «tapiaron a cal y canto las cinco puertas, para que no las destrozasen los soldados franceses", no obstante quedó muy destruido. En el trono José Bonaparte decretó la supresión de todos los conventos (1809), con lo cual el de Frías fue abandonado y sometido a rapina, incluso por los habitantes de la villa. Después de la vuelta de Fernando VII en 1814, los religiosos tornaron al convento arruinado, que hubo de restaurarse. El mayor daño y definitivo acontenció al convento de San Francisco a causa de la desamortización de Mendizabal, impues-

la noticia de la existencia de unos sillares semejantes a los de Rasines, en el convento de San Francisco de Frias. Les agradezco la colaboración prestada.

$"$ El primitivo convento no se hallaba en el enclave actual, por lo que se infiere de la narración del P. Francisco Olano (VILLASANTE, A., Historia de la ciudad de Frias. Burgos 1944, págs. 203-205) "el convento primitivo debió estar en S. Julián, algo distante de la ciudad, junto al Ebro y adonde acudian a lavar sus ropas las mujeres de aquélla, las que con su garrulería y griteríos molestaban no poco a los religiosos del convento, por lo que éstos debieron solicitar y lograr del rey $D$. Sancho IV, que reinó desde 1284 a 1295 , licencia para que se pudiese trasladar a otro paraje más sano, pues el otro era húmedo y próximo a la ciudad, lo que hicieron, instalándose provisionalmente en el antiguo hospital de San Lázaro, junto a la ermita de la Magdalena, si bien no consta la fecha exacta de esta traslación". Sobre esta ubicación y fecha hubo numerosas controversias, por lo que A. Villasante, en su historia de la ciudad de Frias (pág. 205) concluye diciendo "me parece más probable la existencia del convento (aún visible), a la entrada de la ciudad, antes del siglo $\mathrm{xv}$, pues a más de los datos consignados en la crónica, consta que en él hacían entierros de personas pertenecientes a la parroquia, por lo cual en 1480 los PP. Franciscanos tuvieron grave conflicto con el Cabildo Parroquial. Quedamos, pues, sin saber a punto fijo donde se hallaba el primitivo convento, ni el año en que fue traslado por conveniencia, aunque muy probablemente opino que el edificio permanente seria habitado al comenzar el siglo xIv. En D.C.Q.H., Historia de la ciudad de Frias. Vitoria 1887, no consta quién lo construyó ni la fecha de su erección. 


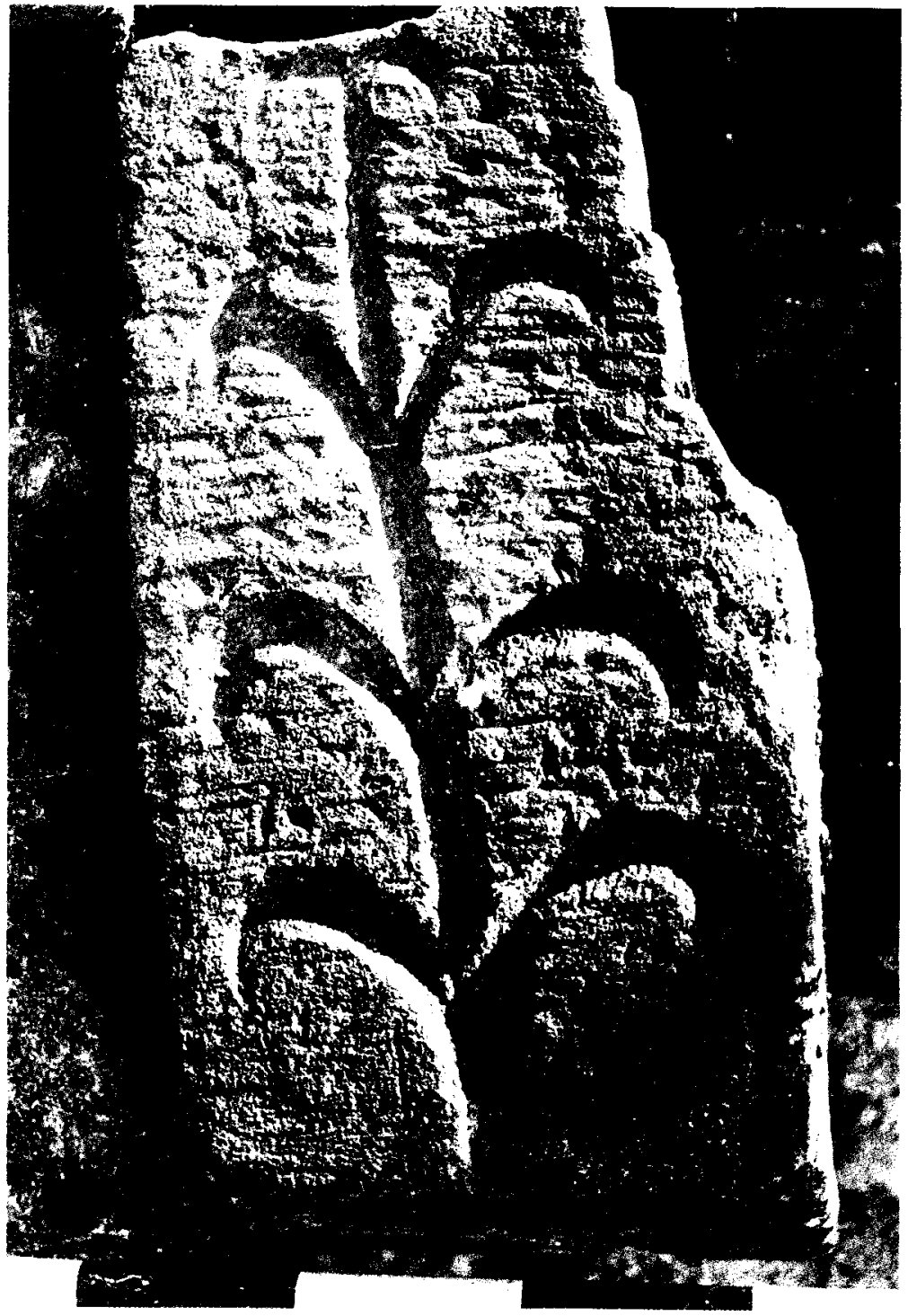

Fig. 3. Sillar grabado del convento franciscano de Frias, Burgos. 


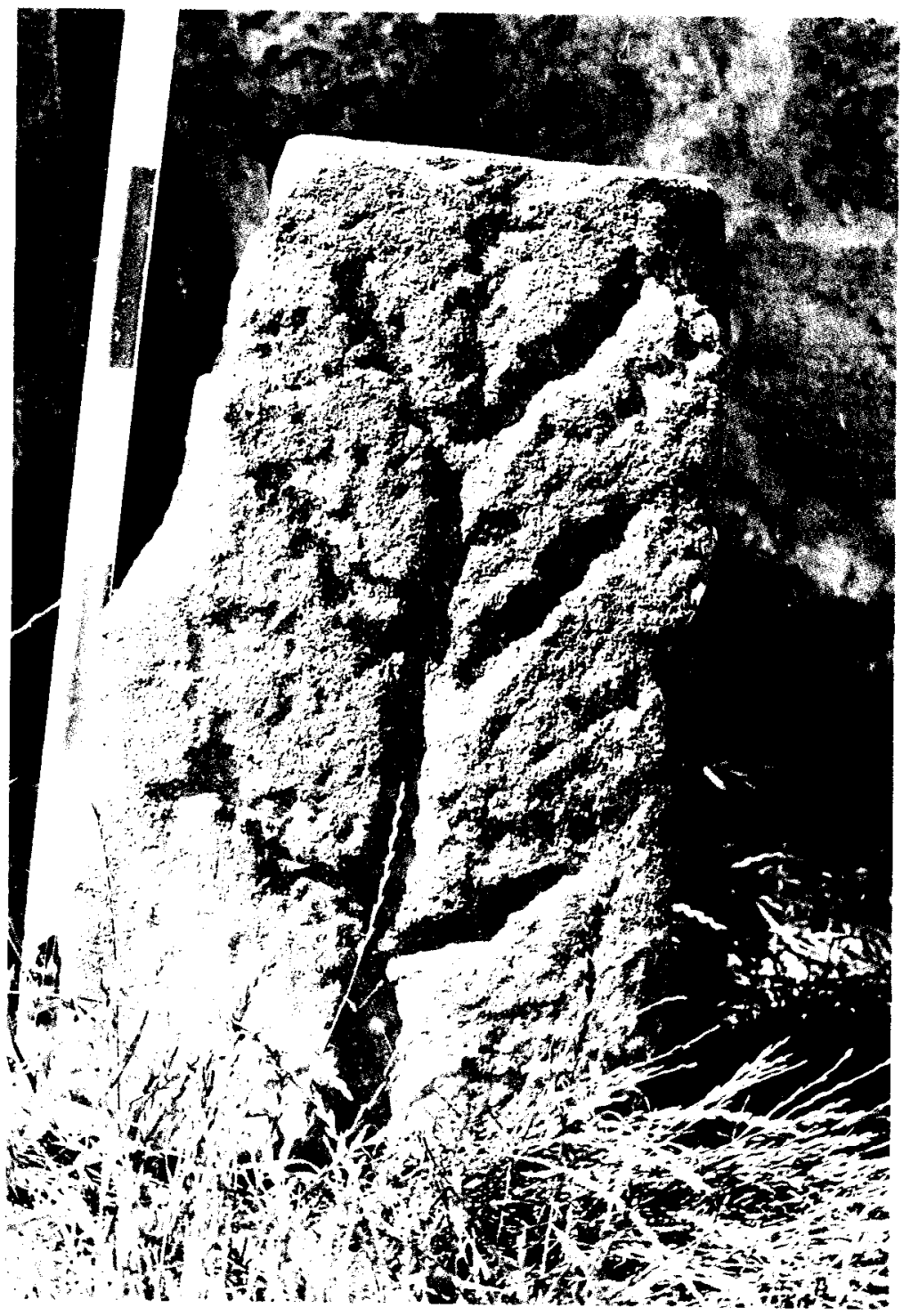

Fig. 4. Sillar grabado del convento franciscano de Frias, Burgos. 


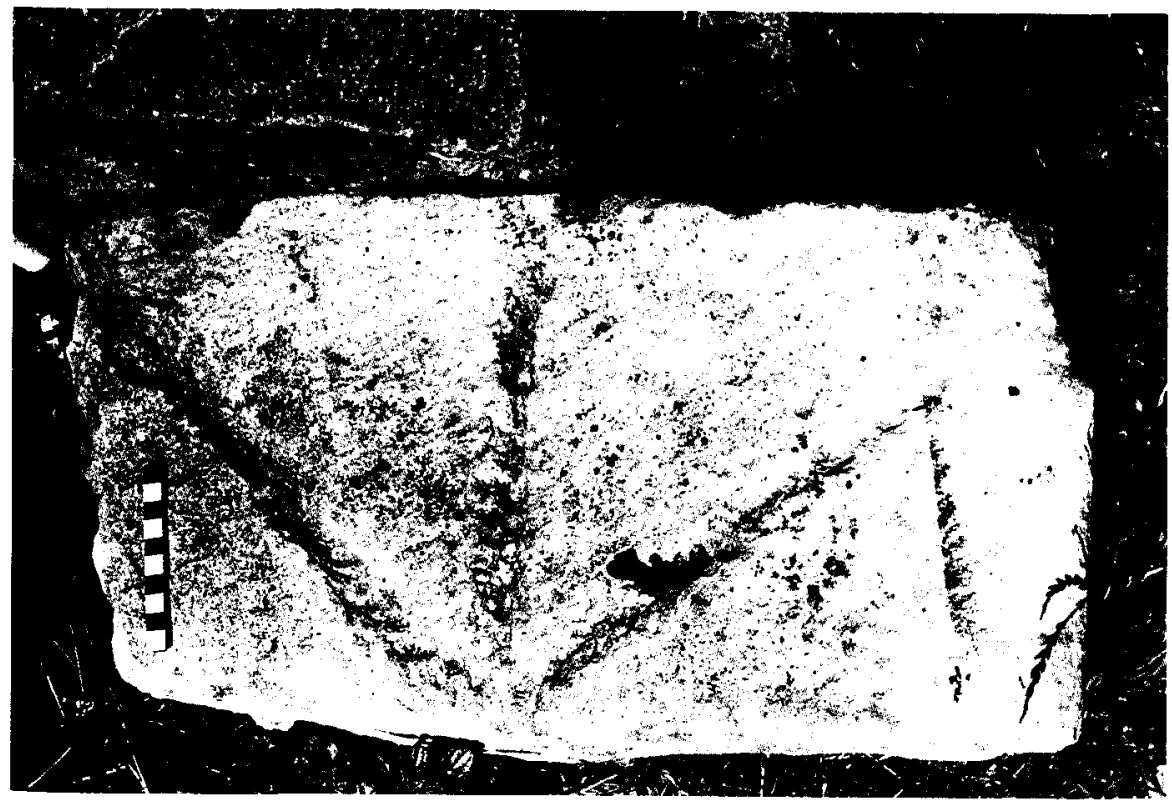

Fig. 5. Sillar grabado del convento franciscano de Frias, Burgos.

ta el 11 de octubre de 1835. En este mismo año se disolvió la comunidad de Frias. El edificio fue comprado por don Antonio Norberto Diaz de Villafranca, quién hizo habitaciones en el frente sur y otros lugares ${ }^{12}$. P. Madoz indica, en 1848 aproximadamente, que el convento de Frías estaba abandonado ${ }^{13}$. En 1933 fue destruido por un incendio y más adelante rehabilitado para viviendas. En una de las reformas se trató de ampliar una puerta renacentista que correspondia a un local industrial. Así pues, se retiraron los sillares y se adecuó la puerta con ladrillo y cemento. Los sillares se dejaron abandonados en una rinconada en el lado derecho de la fachada ${ }^{14}$. Entre numerosos lisos se hallaba una minoria con incisiones esquemáticas vegetales y geométricas.

12 Villasante, A., Historia de la ciudad de Frias, págs. 205-210.

${ }^{13}$ Diccionario Geográfico Estadístico. Madrid 1848.

${ }^{14}$ El equipo que se trasladó a Frias para examinar los sillares estaba compuesto por los dos informantes D. José Angel Rodriguez y Dñ. Elena Helguera asi como por D. Esteban Moreno, D. Pedro Garcia y quien suscribe. Los sillares fueron medidos, fotografiados y sacados el calco. 


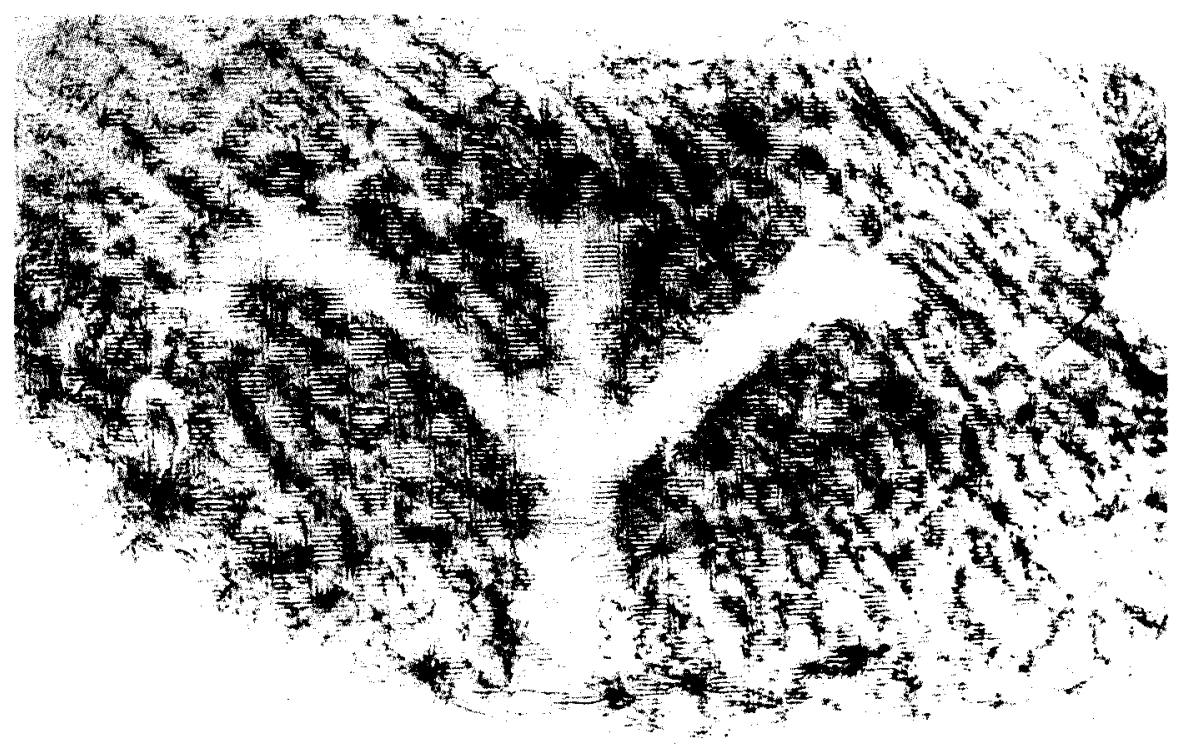

Fig. 6. Calco del grabado de un sillar del convento franciscano de Frias, Burgos.

Efectivamente, cuatro de los sillares, moldurados por pertenecer a la ornamentación de la jamba, ostenta en sus dos caras interiores motivos semejantes a los de los sillares de la iglesia de San Andrés de Rasines. El método de tratamiento es similar. Las superficies fueron desbastadas con puntero de hierro y maceta y posteriormente trabajadas con cincel de hierro. Los grafismos incisos se tallaron solamente con puntero, excepto el de un sillar, cuyo grabado es más perfecto, una palma esquemática, que se trabajó cincelando en V. (Fig. 3).

Es interesante destacar como los grafismos están adecuados al mar$c o$, es decir, están retranqueados con respecto a la moldura, quedando de este modo los grabados descentrados, lo cual no hubiera ocurrido si los sillares fuesen reutilizados de un monumento anterior, pues en este caso el motivo grabado estaría completamente centrado, según las leyes de simetría que rigen desde época primitiva. Ello quiere decir que el dibujo grabado, sea cual fuere su funcionalidad o simbolismo, fue tallado en el momento de usarse, como sillar, para construcción de la puerta renacentista.

En la iglesia gótica de Cereceda, localidad cercana a Rasines, explorando sus ruinas, se encontraron las dovelas de un arco fajón en tierra. 
Examinadas, pudo comprobarse que en las caras de contacto ostentaban, las dovelas pequeñas, una línea incisa profunda y ancha en el centro (Fig. 7). En las dovelas de mayores dimensiones aparecen dos incisiones de las mismas características, e incluso tres. Estos trazos son exclusivamente funcionales y, obviamente, más simples que los de Rasines y Frías, pero cabe la posibilidad de que los tres tengan idéntico sentido en la construcción. Desde luego, las marcas de las dovelas de Cereceda no tienen otra significación que la de facilitar su mejor asentamiento.

También, en las proximidades de la iglesia de Udalla, se localizó un tercer paralelo (Fig. 8).

La iglesia posee numerosos rasgos góticos y ha sido muy modificada. Precisamente, a causa de las transformaciones, es posible que algunos sillares fuesen desplazados de su función original. Uno de ellos se encontró reutilizado, como asiento, en una gran explanada frente a la iglesia. Una de sus caras ostentaba un grabado, consistente en una palma simple, de talla muy deteriorada, tal vez por haber estado durante largo tiempo a la intemperie. Este hecho no ha ocurrido en los grafismos

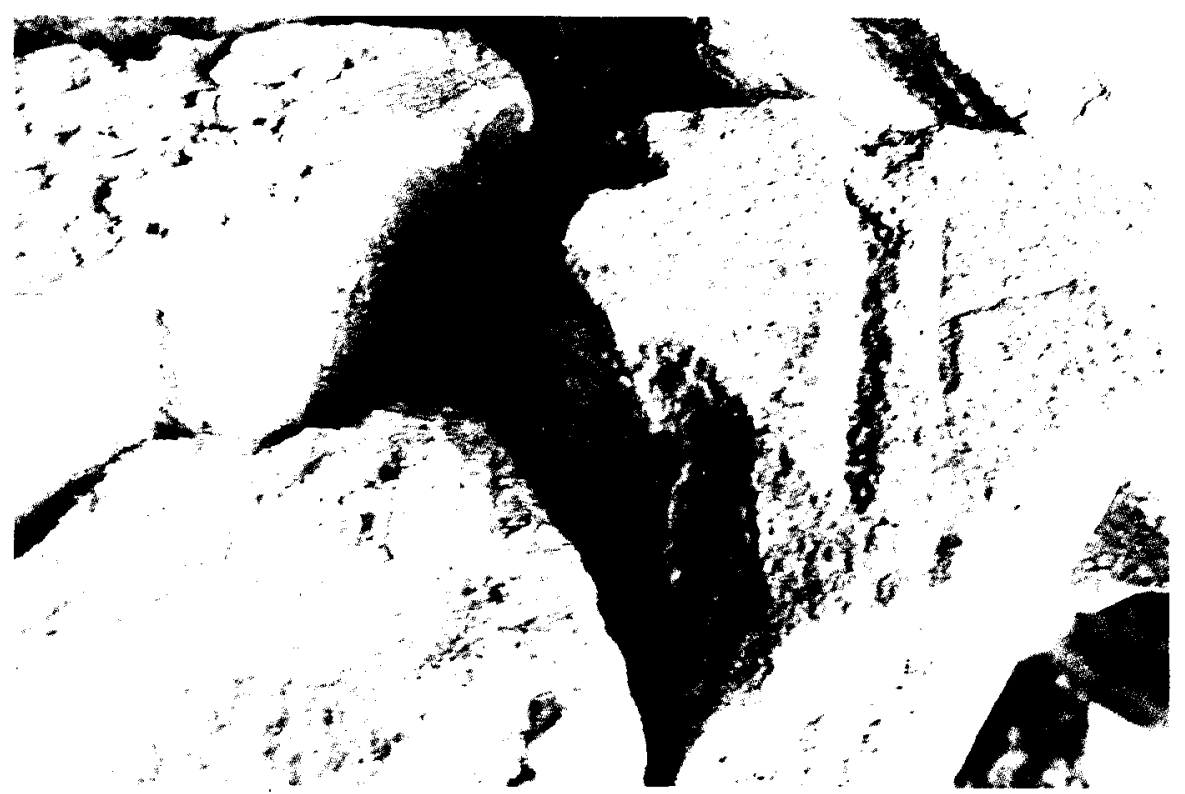

Fig. 7. Sillar grabado de la iglesia de Cereceda, Cantabria. 
de Rasines, Frías y Cereceda. En el grabado no se pudo apreciar la huella del puntero con el que probablemente se conformó. Su funcionalidad o simbología son paralelas a las de Rasines y Frías, aunque la envergadura de los de estos dos puntos no se encuentra en el de Udalla, - los grabados de Cereceda, más antiguos al parecer, son absolutamente funcionales, al margen de cualquier simbolismo, aún desconocido, que puedan tener los de Rasines y Frias-.

Casualmente, en los últimos días de abril, al pasar por los desmontes realizados con motivo de la remodelación del entorno del puente de las Ventas, en Madrid, hallé un sillar de granito, con unas incisiones, en cierto modo semejantes a las citadas (Figs. 9-10). El dibujo, inciso se presenta en una de sus caras anchas. Consiste en una línea horizontal de la que parten dos oblicuas a ambos lados. Es, como puede observarse en la ilustración del mismo, en esquema muy simplista geométrico. Parece que el sillar, junto con otros dos, que no he podido comprobar si tiene incisiones, formaban los escalones de una casa de planta baja. Es un hallazgo de última hora, y no puedo decir más sobre él, en una publicación más extensa, que se está preparando, trataré de localizar su original procedencia, si la hubiera. Mas de lo que se trata es de significar

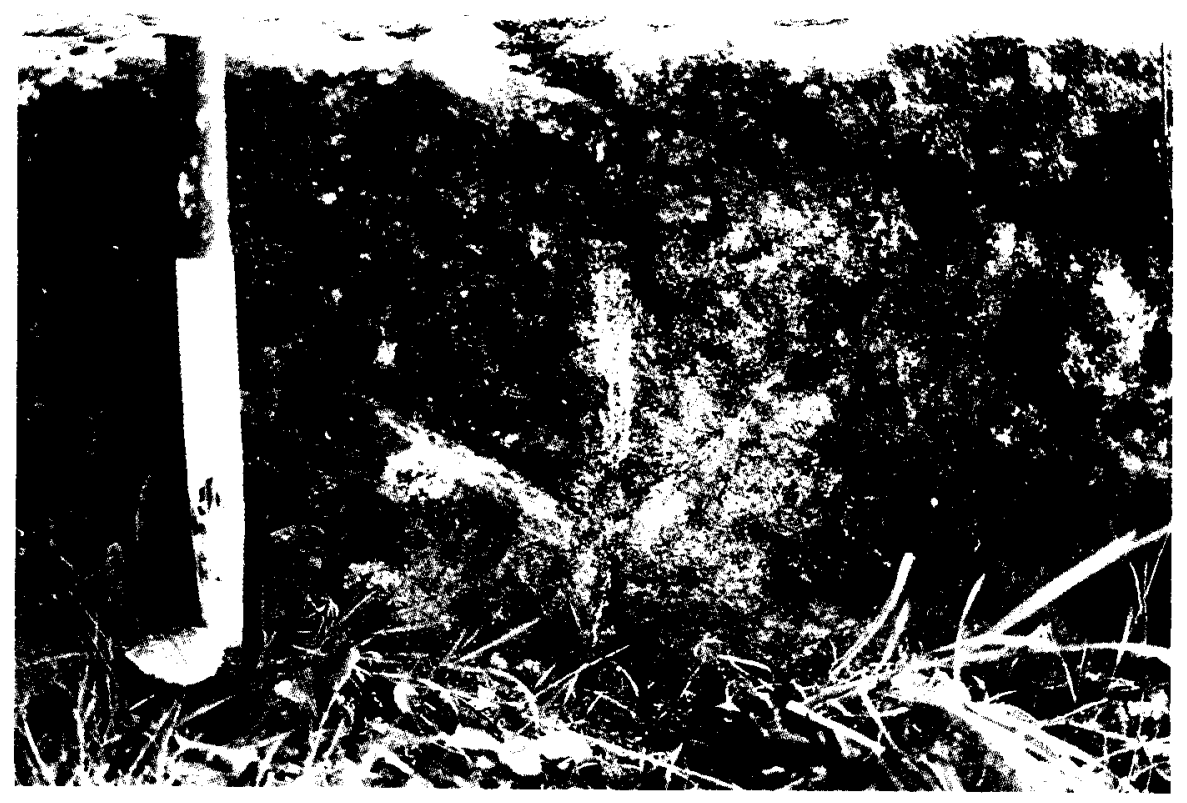

Fig. 8. Sillar grabado hallado en el entorno de la iglesia de Udalla, Cantabria. 


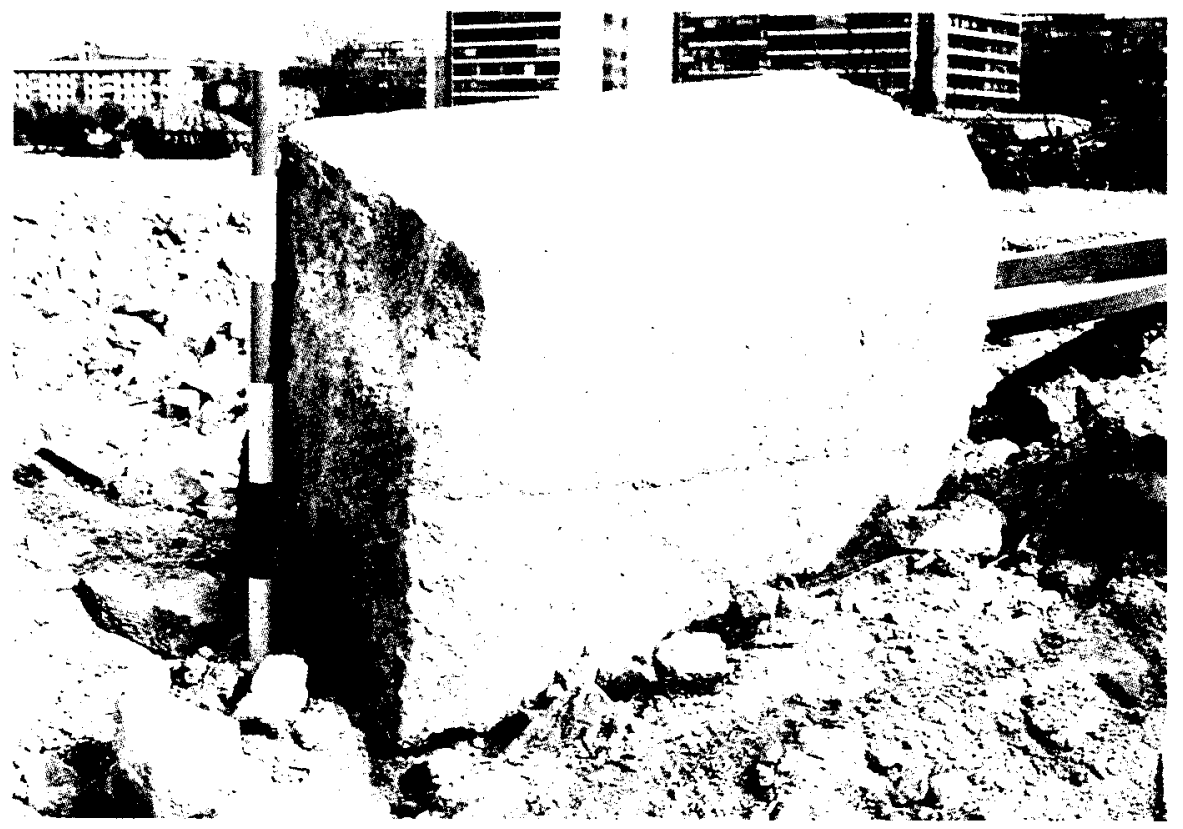

Fig. 9. Sillar grabado, localizado en las obras de acondicionamiento del entorno del puente de las Ventas. Madrid.

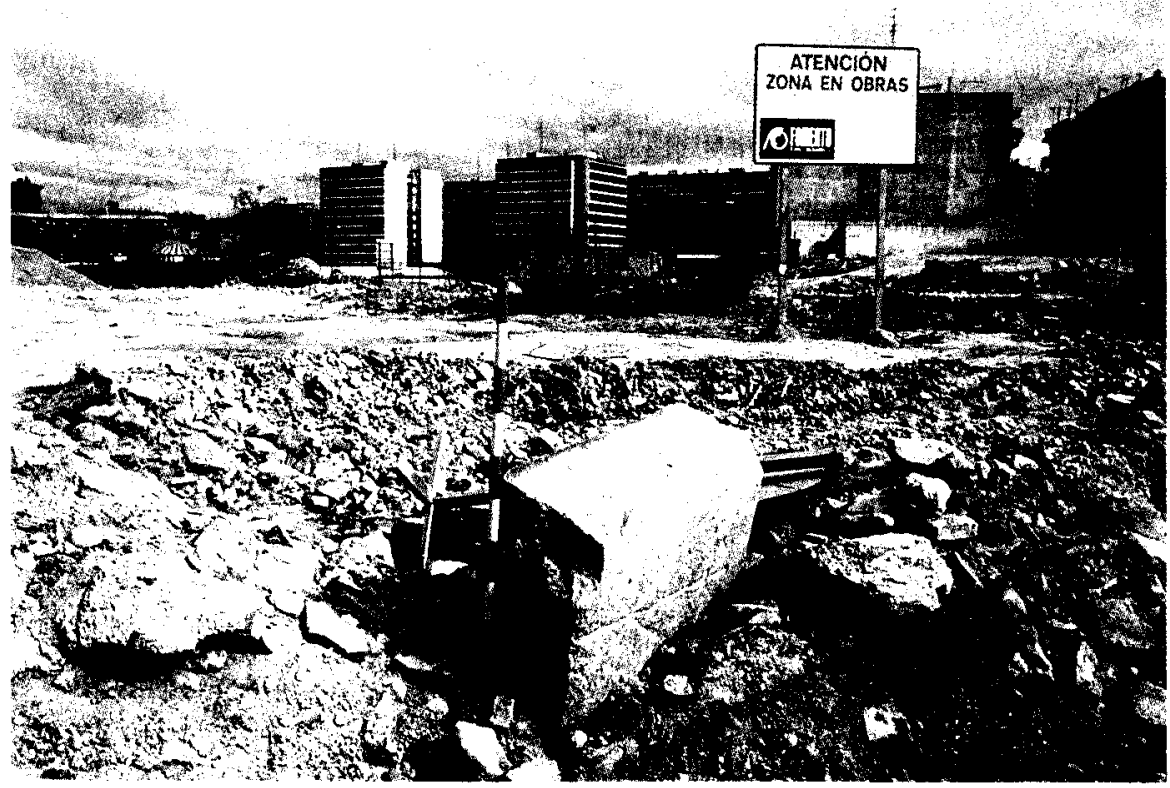

Fig. 10. Vista general del lugar de ubicación. 
cómo estas incisiones en sillares se encuentran en puntos diferentes de la península.

Y para concluir, en el transcurso de una visita al castillo de Corduente, Guadalajara, en el verano de 1991, hallé en el patio, una serie de sillares moldurados. Los mismos tenían, en las caras no vistas, grabados profundos formando espiga, de características semejantes a todos los tratados (Fig. 11). Pertenecieron a los nervios de las bóvedas de lo que fue iglesia renacentista de San Miguel, en Molina de Aragón, Guadalajara. Dicha iglesia fue habilitada, en época actual, por obra y gracia de un alcalde, para viviendas particulares y locales comerciales y, por tanto, las bóvedas fueron deshechas. El propietario del castillo de Corduente, recogió algunas de las piedras molduradas para utilizarlas en la reconstrucción de dicho castillo.

Un mayor estudio de las iglesia y edificios derruidos arrojaría, tal vez, mayor luz sobre el tema de los sillares grabados en las caras interiores, con motivos geométricos simples o vegetales esquemáticos. $Y$ desde luego, una prospección del terreno circundante a la iglesias de San Andrés de Rasines es imprescindible.

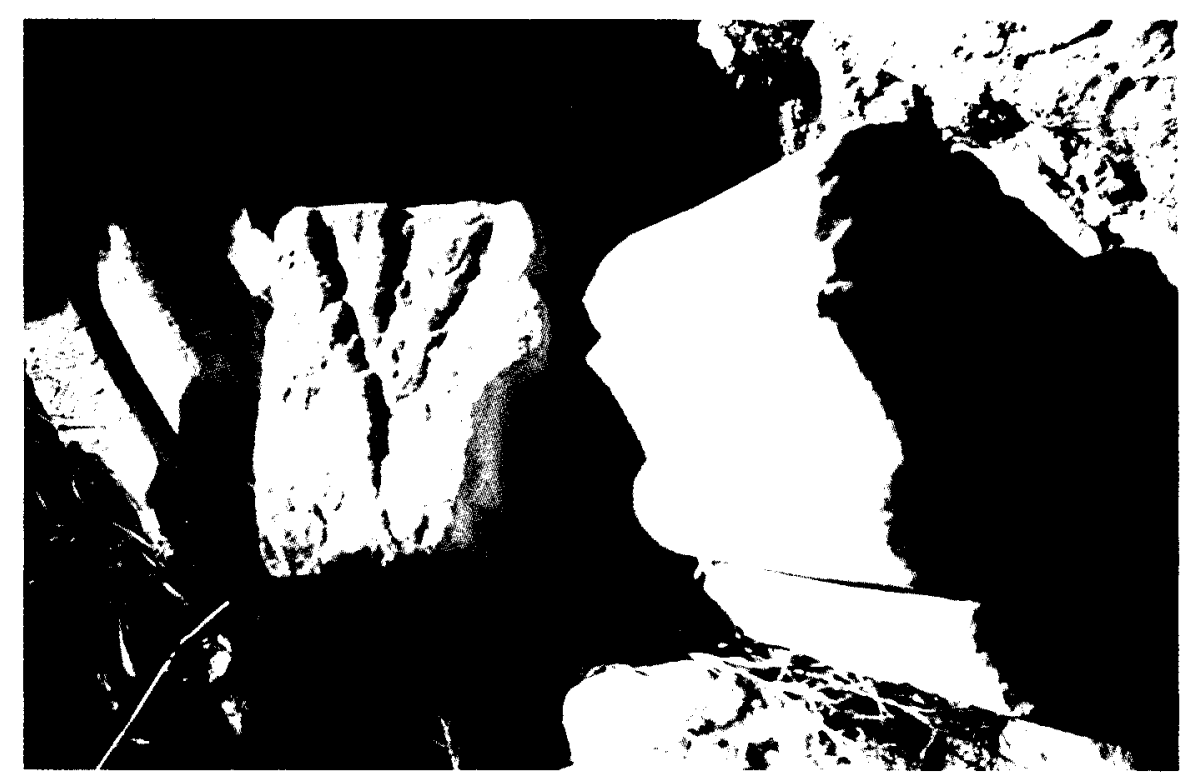

Fig. 11. Sillar grabado de la iglesia de San Miguel, Molina de Aragón, Guadalajara. 